\title{
Production and the Trade Balance in a Small Open Economy
}

\author{
Henry Thompson \\ Auburn University
}

\begin{abstract}
The trade balance is built directly into a factor proportions model of produc tion. A wealth stockpile of the exported good is maintained, growing when the small open economy has a surplus and shrinking with a deficit. Income and prices determine consumption of exports and imports, while production adjusts to maintain full employment and competiti ve pricing. The trade balance effects of an import tariff and an export subsidy (equivalently, a devaluation) depend on factor intensity, factor substitution, demand, and factor endowments. Chang ing factor endowments have no net effect on the trade balance, a reflection of factor price equalization. (JEL Classifications: F11, F 41, F 20) 《Key Words : trade balance, small open economy, tariff, subsidy, factor endowments>
\end{abstract}

\section{Introduction}

General equilibrium trade theory makes the assumption that trade is balanced to close the model of a small open economy. Trade imbalance has been studied in the context of macroeconomic models, as reviewed by

\footnotetext{
* Correspondence Address: Department of Economics, Auburn University, AL 36849, U.S.A., (Fax) +1-334-844-4615, (E-mail) hthompsn@business.auburn.edu.

* Thanks for suggestions go to M ichael Anderson and others at the 1996 meeting of the Southern Economics Association.

(C)1999 - Institute for International Economics, Sejong Institution. All rights reserved.
} 
Kemp [1964], Goldstein and Khan [1985], and Frenkel, Razin, and Yuen [1996]. The present paper introduces the potential of trade imbalance accomodated by a wealth stockpile of the exported good. The stockpile collects trade surpluses and pays trade deficits, but has no effects on production and trade in the economy. The factor proportions model of production with two factors and two goods is used as the foundation to analyze the trade balanace effects of a tariff, a subsidy, and factor endowment changes.

A tariff in such an economy lowers the level of imports as it redistributes income between productive factors according to the Stolper-Samuelson theorem. Production of the exported good falls and its consumption increases, causing the level of exports to fall. The net effect of a tariff on the trade balance depends on price effects in consumption, endowment levels, factor intensity, and factor substitution.

An export subsidy in the form of a price support causes production of the exported good to increase and its consumption to fall. I mports also rise as production falls and consumption increases with the lower relative price of imports. The net effect on the trade balance depends on the same array of fundamental properties in the general equilibrium model.

Factor endowment changes have no effect on factor prices, the factor price equalization result. Outputs do all of the adjusting according to the Rybczynski pattern. Income rises with an increased endowment, causing consumption to rise. The surprise is that consumption changes exactly offset the effects of changing outputs on the trade balance.

The present model allows examination of trade balance issues in the context of a well known production structure without the specific introduction of a financial sector or intertemporal decision making. The combination of an export subsidy with an import tariff is equivalent to a devaluation. The condition which determines whether such a devaluation raises the trade balance, the "real" $M$ arshall-Lerner condition, is derived.

\section{The Balance of Trade and Income}

Let good 1 be the export and good 2 the import. The level of exports is $x_{1}-$ $c_{1}$, where $x_{1}$ is output and $c_{1}$ is consumption of the exported good. The level of imports is $c_{2}-x_{2}$. The balance of trade is measured in world prices, 


$$
B=p_{1}\left(x_{1}-c_{1}\right)-p_{2}\left(c_{2}-x_{2}\right) \text {. }
$$

Prices of each good are included rather than the relative price because of explicit interest in both import tariffs and export subsidies. Goods are rescaled so $p_{1}=p_{2}=1$, and $B=\left(x_{1}-c_{1}\right)-\left(c_{2}-x_{2}\right)$. Changes in the trade balance are summarized

$$
\mathrm{dB}=\left(\mathrm{dx}_{1}+\mathrm{dx}_{2}\right)-\left(\mathrm{dc}_{1}+\mathrm{dc}_{2}\right) .
$$

Figure 1 illustrates the potential of imbalanced trade. Good 1 is exported at the term of trade tt. Consumers face world prices tt and would consume at point $B$ with balanced trade. Under a deficit, consumption would take place at a point like $D$. At both points $B$ and $D$, a homothetic utility function between the two goods is maximized. There are more imports of good 2 and less exports of good 1 at point $D$ relative to point $B$. Imports $D F=A E$ of good 2 must be paid for by CE units of good 1, CF exported from production and $E F$ from the stockpile. A surplus would occur with consumption along the ray from the origin below point $B$.

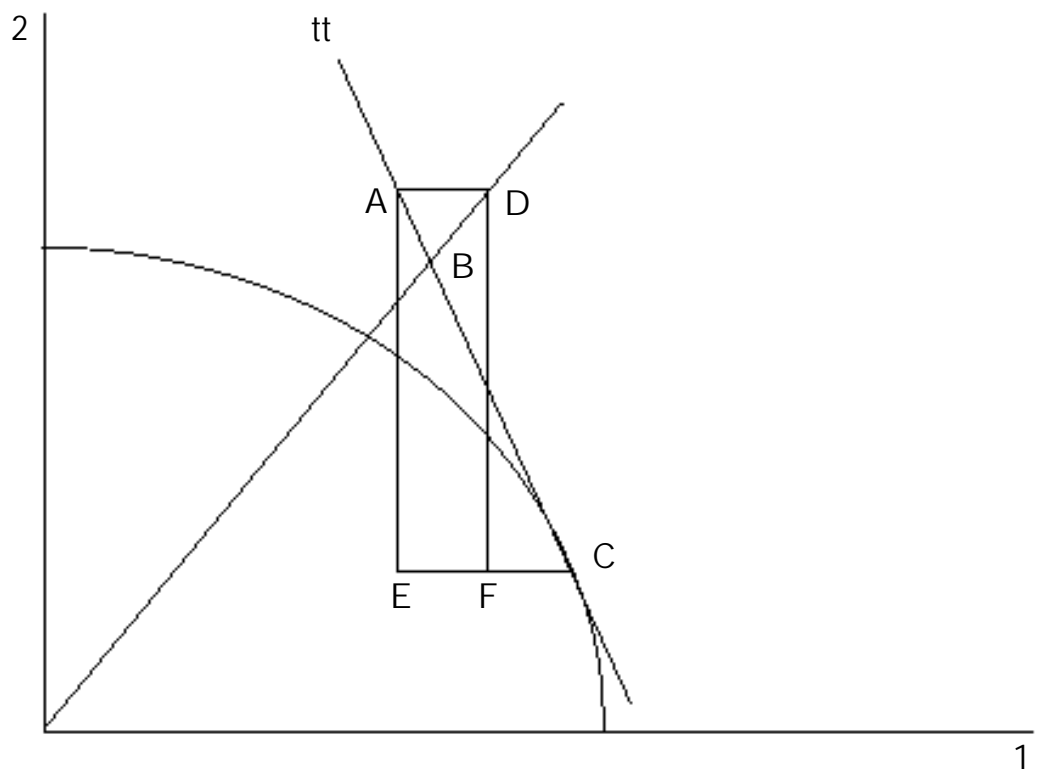

Figure 1 
Domestic and world prices are related through an export subsidy $(1+s) p_{1} *=p_{1}$ and an import tariff $(1+t) p_{2} *=p_{2}$, with the exchange rate normalized to one. Export subsidies raise the domestic price above the world price through a price support. Note that $p_{1}=1+s$ and $p_{2}=1+t$. Concentrate on price changes due to trade policy: $\mathrm{dp}_{1}=\mathrm{ds}$ and $\mathrm{dp} \mathrm{p}_{2}=\mathrm{dt}$. In a small open economy, national income is written $y=\Sigma_{j} p_{j} c_{j}+B=(1+s) c_{1}+(1+t) c_{2}+x_{1}-c_{1}$ $\mathrm{C}_{2}+\mathrm{x}_{2}=\mathrm{SC}_{1}+\mathrm{tc}_{2}+\mathrm{x}_{1}+\mathrm{x}_{2}$. If $\mathrm{s}=\mathrm{t}=0$, then $\mathrm{y}=\mathrm{x}_{1}+\mathrm{x}_{2}$.

Partial equlibrium analysis suggests that an import tariff or export subsidy would raise the trade balance. Higher prices raise output and lower consumption of each good, and would appear to have a positive effect on the trade balance $B$. There are, however, changes on the supply side in the general equilibrium and an increase in $B$ is not gauranteed. The $M$ arshall-Lerner condition makes this point in terms of summary import and export elasticities, which contain no explicit information about production or for that matter demand.

Consumption of each good depends on the prices of both goods as well as income: $c_{j}=c_{j}\left(p_{1}, p_{2}, y\right), j=1,2$. The own substitution effects are negative, $c_{11}, c_{22}<0$, and the cross effects are positive, $c_{12}, c_{21}>0$. Higher income raises the consumption of both goods: $c_{j y}>0$. Consumption of either good in the small open economy changes according to

$$
d c_{j}=c_{j 1} d s+c_{j 2} d t+c_{j y} d y .
$$

Combining (2) and (3),

$$
\mathrm{dB}=\mathrm{dx} \mathrm{x}_{1}+\mathrm{dx}_{2}+\gamma_{1} \mathrm{ds}+\gamma_{2} \mathrm{dt}-\gamma_{\mathrm{y}} \mathrm{dy},
$$

where $\gamma_{1} \equiv-\left(c_{11}+c_{21}\right), \gamma_{2} \equiv-\left(c_{12}+c_{22}\right)$, and $\gamma_{y} \equiv c_{1 y}+c_{2 y}$. Own substitution effects are assumed to be larger than the cross effects, which implies $\gamma_{1}>0$ and $\gamma_{2}>0$. Income $y$ is spent on both goods: $y=\Sigma_{j} p_{j} c_{j}$. A change in income (with prices constant) is matched by changes in consumption: $d y=\Sigma_{j} p_{j} d c_{j}$. Divide both sides by dy to find $1=\Sigma_{j} p_{j} c_{j y}=c_{1 y}+c_{2 y}$, with both prices normalized to one. It follows that $\gamma_{y}=1$.

Changes in income can be written $d y=\Sigma_{i} w_{i} d v_{i}+\Sigma_{i} v_{i} d w_{i}$, which is combined with (4) to find the last equation in the comparative static system (6). The balance of trade is thus incorporated into the familiar comparative static model of production and trade for a small open economy.

In the comparative static analysis, assume $B=0$ in the original equilibri- 
um. In the comparative static model, only small changes are considered. Trade imbalances cause changes in the wealth stockplie $W$ : $B=d W$. If $B<0$, the home country depletes its wealth stockpile of the exported good. If $B>$ 0 , the stockpile grows. Disregard wealth effects on consumption. The stockpile is assumed to be large enough to handle trade deficits which occur in the comparative statics. The grander problem of maintaining an optimal international stockpile is ignored. The possibility of corner solutions, driving $W$ to zero or infinity, is also ignored.

\section{The Comparative Static Model of Production with a Trade Balance}

The comparative statics of factor proportions models is developed by Jones [1965], Jones and Scheinkman [1977], Chang [1979], Takayama [1982], and others. Full employment of factor $i$ is written $v_{i}=\Sigma_{j} a_{i j} x_{j}$, where $a_{i j}$ is the cost minimizing amount of factor $i$ used in the production of good $j$. Factors are rescaled so $a_{i 1}=1$. Differentiate the full employment condition and introduce substitution terms to find $d v_{i}=\Sigma_{k} S_{i k} d v_{k}+\Sigma_{j} a_{i j} d x_{j}$. Substitution terms $S_{i k}=\Sigma_{j} x_{j} \partial a_{i j} / \partial w_{k}$ have zero row sums due to linear homogeneity: $S_{11}+$ $S_{12}=S_{21}+S_{22}=0$. They are also symmetric due to Shephard's lemma and the Taylor formula: $\mathrm{S}_{12}=\mathrm{S}_{21}$. F or summary notation, $\mathrm{S} \equiv-\mathrm{S}_{11}=\mathrm{S}_{12}=\mathrm{S}_{21}=$ $-S_{22}>0$. The two full employment conditions lead to the first two equations in the comparative static model (6). Competitive pricing means price equals average cost: $p_{j}=\Sigma_{i} a_{i j} w_{i}$. Differentiate and use the cost minimization envelope result to find the third and fourth equations in (6). Note that price changes are reduced to changes in subsidies or tariffs.

Figure 2 summarizes the production structure and the normalizations. Note that $a_{11}=a_{21}=1$. Assume factor 1 is used intensively in good 1 . The factor intensity condition $a_{11} / a_{21}>a_{12} / a_{22}$ implies $a_{22}>1>a_{12}$. Factor intensity is summarized by the term $\beta=a_{22}-a_{12}>0$, which says exports are intensive in factor 1 . The isocost line in Figure 2 supports a unit value isoquant for each good, $x_{j}=1 / p_{j}$, at the two intersections along the isocost line. The absolute value of the slope of the isocost line is written

$$
\mathrm{w}_{2} / \mathrm{w}_{1}=\left(1-\mathrm{a}_{12}\right) /\left(\mathrm{a}_{22}-1\right) \text {. }
$$

It follows directly that $w_{1}+w_{2}=w_{2} a_{22}+w_{1} a_{12}$, which equals $p_{2}$ in the stan- 
dardization. Thus, $\mathrm{w}_{1}+\mathrm{w}_{2}=1$, short of a tariff or subsidy.

The comparative static system is written

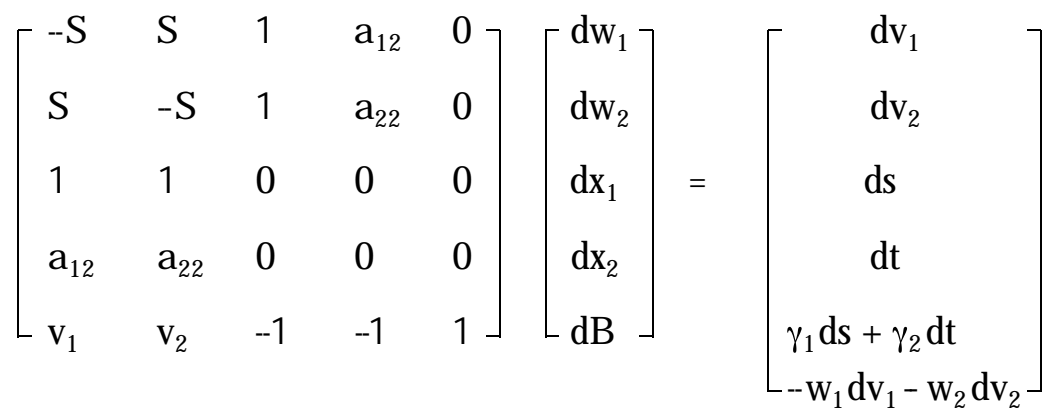

Exogenous changes in factor endowments, subsidies, and tariffs are collected on the right hand side of (6). Adjustments in factor prices, outputs, and the balance of trade appear in the vector of endogenous variables. Divide both sides of (6) by the change in an exogenous variable, and use Cramer's rule to find the comparative static partial derivatives of the model. The determinant of the system is $\Delta=\beta_{2}$.

\section{Effects on the Trade Balance}

Table 1 presents the comparative static results of the underlying factor proportions production structure. In Table $1, \alpha \equiv a_{12}+a_{22}>0$. Results are symmetric around the main diagonal. The $\partial \mathrm{w} / \partial \mathrm{v}$ zeros indicate the factor price equalization result. Signs of the $\partial \mathrm{X} / \partial \mathrm{v}$ Rybczynski and $\partial \mathrm{w} / \partial \mathrm{s}$, $\mathrm{t}$ StolperSamuelson terms follow the pattern of factor intensity. The $\partial \mathrm{x} / \partial \mathrm{s}$, t terms indicate a concave production frontier. The comparative static results in Table 1 are identical to those with a zero balance of trade.

Table 1

Comparative Statics

\begin{tabular}{|c|c|c|c|c|}
\hline & $\partial \mathrm{w}_{1}$ & $\partial \mathrm{w}_{2}$ & $\partial \mathrm{x}_{1}$ & $\partial \mathrm{x}_{2}$ \\
\hline$\partial \mathrm{v}_{1}$ & 0 & 0 & $\mathrm{a}_{22} / \beta$ & $-1 / \beta$ \\
\hline$\partial \mathrm{v}_{2}$ & $\cdot$ & 0 & $-\mathrm{a}_{12} / \beta$ & $1 / \beta$ \\
\hline$\partial \mathrm{s}$ & $\cdot$ &. & $\mathrm{S}^{2} / \Delta$ & $-2 \mathrm{~S} \alpha / \Delta$ \\
\hline$\partial \mathrm{t}$ &. &. &. & $4 \mathrm{~S} / \Delta$ \\
\hline
\end{tabular}


Table 2

Trade Balance Effects

\begin{tabular}{|c|c|}
\hline$\alpha$ & $\partial \mathrm{B}$ \\
\hline$\partial \mathrm{v}_{1}$ & $\left(\mathrm{a}_{22}-1-\beta \mathrm{w}_{1}\right) / \beta=0$ \\
\hline$\partial \mathrm{v}_{2}$ & $\left(1-\mathrm{a}_{12}-\beta \mathrm{w}_{2}\right) / \beta=0$ \\
\hline$\partial \mathrm{s}$ & $\left(\gamma_{1} \beta^{2}-\alpha \mathrm{S}(2-\alpha) \mathrm{s}-\beta \mathrm{v}_{\mathrm{s}}\right) / \Delta$ \\
\hline$\partial \mathrm{t}$ & $\left(\gamma_{2} \beta^{2}-2 \mathrm{~S}(2-\alpha)-\beta \mathrm{v}_{\mathrm{t}}\right) / \Delta$ \\
\hline
\end{tabular}

Table 2 presents the comparative static trade balance effects. The term $\partial B / \partial v_{1}$ can be written $a_{22}-1-\left(a_{22}-a_{12}\right) w_{1}=a_{22}\left(1-w_{1}\right)-1+a_{12} w_{1}=a_{22} w_{2}$ $+a_{12} w_{1}-1$. The negative of the slope of the isocost line in Figure 2 can be written $w_{2} / w_{1}=\left(1-a_{12}\right) /\left(a_{22}-1\right)$, which implies $w_{1} a_{12}+w_{2} a_{22}=w_{1}+w_{2}=1$. Thus, $\partial B / \partial v_{1}=0$. Similarly, $\partial B / \partial v_{2}=0$. Endowment changes have no effect on a zero trade balance. $F$ actor prices are not affected due to the factor price equalization property, with factor demand adjustments exactly offsetting factor supply changes. Outputs adjust when endowments change, but consumption levels exactly compensate and the trade balance is not affected.

As an example, consider a small increase in the endowment $v_{1}$. Start where $B=0$. From Table $1, x_{1}$ rises by $a_{22} / \beta$ and $x_{2}$ falls by $1 / \beta$. Given that $\mathrm{p}_{1}=\mathrm{p}_{2}=1$, the trade balance would rise with these output adjustments: $d B=$ $\left(a_{22}-1\right) / \beta>0$. Income, however, increases according to $d y=w_{1} d v_{1}>0$. Consumption of both goods rises, but consumption of the export must rise by a greater amount in order for the trade balance to remain at zero. In order words, $\mathrm{dc}_{1}>\mathrm{dc}_{2}>0$. This property amounts to comparative static neutrality of the trade balance with respect to endowments.

An export price support can raise or lower the trade balance. In Table 1, note that an export subsidy raises both $x_{1}$ and $w_{1}$, while lowering $x_{2}$ and $w_{2}$. Production shifts toward the export industry with the subsidy, and the relative price of the factor used intensively in the export sector rises. In Table 2 , $v_{s} \equiv a_{22} v_{1}-a_{12} v_{2}$, which is positive from Figure 1 . A higher $\gamma_{1}$ and a lower $v_{s}$ make $\partial \mathrm{B} / \partial \mathrm{s}$ larger and more likely positive. The sign of $2-\alpha$ is the same as the sign of $w_{2}-w_{1}$ from (5). The effect of a higher degree of substitution $\mathrm{S}$ depends on which factor has the higher price. Suppose the factor used intensively in exports is paid more than the other, $w_{1}>w_{2}$, which implies 2 - 
$\alpha<0$. A higher $S$ then makes $\partial B / \partial S$ larger. The effect of $\alpha$ on $\partial B / \partial S$ depends on the sign of $\partial(\partial B / \partial S) / \partial \alpha=2 S(\alpha-1)$, which is positive since $a_{22}>$ 1 and $\alpha>1$. A higher $\alpha$ makes $\partial B / \partial s$ larger and more likely positive. The effect of a higher $\beta$ on $\partial B / \partial s$ is ambiguous.

A subsidy is more likely to raise the trade balance the larger the price effects of the exported good on consumption, the larger the intensity difference across goods, the smaller the income effects on consumption, and the smaller the economy's relative abundance in the factor used intensively in export production. Export subsidies may not improve the trade balance, as suggested by partial equilibrium analysis.

The effect of a tariff on the trade balance is similarly analyzed. In Table 2 , $v_{t} \equiv v_{2}-v_{1}>0$. A higher $c_{2}$ or $\alpha$, and a smaller $v_{t}$ result in a more positive $\partial B / \partial$ t. If $w_{1}>w_{2}$, a higher $S$ makes $\partial B / \partial t$ smaller. Again, a larger $\beta$ has an ambiguous effect on $\partial B / \partial t$. Whether tariffs improve the trade balance depends on the production and consumption characteristics of the economy.

Combining an export price subsidy with an import tariff is identical to a currency devaluation. The total effect on the trade balance of this effective devaluation is

$$
\partial \mathrm{B} / \partial \mathrm{S}+\partial \mathrm{B} / \partial \mathrm{t}=\left(\gamma_{1}+\gamma_{2}\right) \beta^{2}+\mathrm{S}(2-\alpha)^{2}-\beta\left(\mathrm{v}_{\mathrm{s}}+\mathrm{v}_{\mathrm{t}}\right) .
$$

The trade balance may rise or fall under the combination of a subsidy and tariff. The condition in (7) is equivalent to the familiar $M$ arshall-Lerner condition, but contains detail about the underlying structure of production and consumption. A higher $\gamma_{1}, \gamma_{2}$, or $\mathrm{S}$, and a lower $\alpha_{1}, \mathrm{v}_{\mathrm{s}}$, or $\mathrm{v}_{\mathrm{t}}$ all favor an increase in the trade balance due a devaluation. The effect of a change in factor intensity $\beta$ is ambiguous. Larger own consumption price effects and smaller cross effects favor a larger term $\gamma_{1}+\gamma_{2}$ and a more positive influence in (7). A higher degree of input substituion $S$ also favors a more positive influence. Examining Figure 2, when $w_{1}>w_{2}$ a lower $\alpha$ means a smaller production cone or more similar production isoquants between the two goods. Finally $v_{s}+v_{t}=\left(a_{22}-1\right) v_{1}+\left(1-a_{12}\right) v_{2}>0$ is lower when either the production cone is smaller or there is less of either factor endowment.

Equation (7) shows why the M arshall-Lerner condition would hold in the $2 \times 2$ factor proportions model of production and trade. Similar conditions can be derived for specific factor models and other general equilibrium 
models. The $\mathrm{M}$ arshall-Lerner condition is typically derived in a summary macroeconomic model, while equation (7) is more primitive in that it relates to production and consumption conditions observable at the time of a devaluation.

A move toward free trade, lowering subsidies and tariffs, is written as the negative of (7). Lower $\gamma_{1}, \gamma_{2}$, or $S$, and higher $\alpha_{1} v_{s}$ or $v_{t}$ all favor an increase in $B$ due to the removal of a subsidy and a tariff. There is no gaurantee of the effect of a move toward free trade on the trade balance, even for the small open economy. If two economies move toward bilateral free trade, the terms of trade effects would enter the calculus.

\section{Conclusion}

The main lesson of the present paper is that the effects of imposing or removing tariffs and subsidies on the trade balance depend on an array of properties in general equilibrium, apart from effects on the terms of trade. Trade imbalances may have a counterpart in capital flows, but these capital flows embody eventual real effects. There is no presumption in general equilibrium as in partial equilibrium that tariffs or subsidies raise the trade balance.

The effects of a move toward free trade on the trade balance should be analyzed in terms of consumption price elasticities, substitution in production, and factor endowments. This approach to the trade balance through the fundamentals of production has more potential than summary macroeconomic models which must miss most of what occurs as production in the economy adjusts.

The present model beings with balanced trade, and examines what must happen to the trade balance due to endowment changes, subsidies, or tariffs. Effects of a nonzero initial trade balance can be included in the present model, as can wealth effects on consumption. In a two country model of the trade balance, the terms of trade would adjust between the two "large" economies. The choice of the optimal trade balance, or debt position, can be embedded in a dynamic long run model of production with optimal lending and borrowing. 


\section{References}

Chang, Winston [1979], "Some Theorems of Trade and General Equilibrium with M any Goods and Factors," Econometrica 47; pp. 709-26.

Frenkel, Jacob, Assaf Razin, and Chi-Wa Yuen [1996], Fiscal Policies and Growth in the World Economy, (3rd ed.), Cambridge: M IT Press.

Goldstein, M orris and M ohsin S. Kahn [1985], "Income and Price Effects in F oreign Trade," in Handbook of International E conomics II, (eds.), by Ron J ones and Peter Kenen, Amsterdam: Elsevier Science Publishers. Jones, Ron [1965], "The Structure of Simple General Equililbrium M odels," Journal of Political Economy; pp. 57-72.

Jones, Ron and J osé Scheinkman [1977], "The Relevance of the Two-Sector Production Model in Trade Theory," Journal of Political E conomy; pp. 909-35.

Kemp, M urray [1964], The Pure Theory of International Trade, Englewood Cliffs: Prentice Hall.

Takayama, Akira [1982], "On Theorems of General Competitive Equilibrium of Production and Trade - A survey of Some Recent Developments in the Theory of International Trade," Keio Economic Studies 19, No.1, pp. 1-37. 